\title{
Development of lag time and time of concentration for a tropical complex catchment under the influence of long-term land use/land cover (LULC) changes
}

\begin{abstract}
Lag time (tL) and time of concentration (Tc) are essential time parameters used in hydrological flood-flow design methods for estimating peak discharge and flood hydrograph shape. They form the basis of a number of hydrological models used among the scientists. Kelantan River basin, Malaysia, is a tropical catchment receiving heavy monsoon rainfall coupled with intense land use/land cover (LULC) changes making the area consistently flood prone thereby deteriorating water balance in the area. The most recent is that of December 2014 flood which lead to catastrophic loss of huge amount of properties worth millions of Malaysian ringgit. In view of this, the current research was conducted with the aim of developing (1) tL and Tc based on 1984, 2002, and 2013 LULC conditions; (2) a relationship between $\mathrm{tL}$ and $\mathrm{tL}$ parameters; and (3) a relationship between $\mathrm{tL}$ and Tc among different LULC conditions. Kelantan River basin was first delineated into four major catchments, viz., Galas, Pergau, Lebir, and Nenggiri, due to its large size (approximately 13,100 km2). Soil map and LULC change maps corresponding to 1984, 2002, and 2013 were used for the calculation of $\mathrm{CN}$ values while NRCS lag equation was used for the estimation of tL and Tc. The results showed that deforestation for logging activities and agricultural practices were the dominant LULC changes across the watershed. Low values of both $\mathrm{tL}$ and Tc were obtained across the catchment which are typical for a tropical monsoon catchment characterized with high runoff and short peak discharge. Results of tL and Tc in this study are not affected by LULC changes in the basin. Slope was observed to be highly correlated with tL. Correlation coefficient was used to determine the relationship between tL and tL factor, and hydraulic length and slope $(\mathrm{L} \sqrt{ } \mathrm{S})$. The results showed high correlation in all the catchments from 1984 to 2013 except for Lebir catchment where a moderate correlation was observed. The findings of this study may be useful to water resource planners in controlling water loss for future planning.
\end{abstract}

